\section{PO-0945 HOW TO DEAL WITH ABUSES OF THE INTERNET IN ADOLESCENTS?}

B Stanimirov, T Njegomir-Eremic, R Obradovic, S Basic. Pediatrics, Healt Center Novi Sad, NOVI SAD, Serbia

\subsection{6/archdischild-2014-307384.1566}

Introduction The modern world of living, raises the question of recognition of new forms of addiction, such as the internet and gambling.

The aim of the study point to the excessive use of the Internet and gambling in adolescents Novi Sad.

Material and methods Our target group were students aged 14-18 years, from 2009 to 2012 th year, which are treated in the school clinic Health Centre Novi Sad. Students filled in an anonymous questionnaire with the following data: patient sex, age, how many hours a day they spend in internet gambling and how neglecting school work.

Results The survey covered the 589 (87.49\%), adolescent girls than that number was 270 (45.78\%) boys and 319 $(54.22 \%)$. On the internet daily for more than an hour of his time $284(48.25 \%)$, during the evening and late at night not sleeping 189 (32.16\%). Neglect of homework assignments for the internet is present in $162(27.56 \%)$ students. When asked if they would stop visiting the Internet responded to the 90 (15.26\%) students with no $150(25.47 \%)$ students. Number of students who gamble with 74(12.63\%). Consciousness to neglect their school and family obligations answer is 128 (21.76\%) students.

Conclusion Every day, unfortunately, a growing number of children who are dependent on internet-new lifestyle. To solve this problem it is necessary to daily physical activity or at least three times a week, socialising and communication with peers live, instead of staying long hours at the computer.

\section{PO-0946 UNETHICAL COMPUTER USING BEHAVIOURS OF TURKISH HIGH SCHOOL STUDENTS}

${ }^{1}$ M Kurtuncu, ${ }^{2} \mathrm{~B}$ Demirbag, ${ }^{3} \mathrm{H}$ Yildiz, ${ }^{4} \mathrm{~L}$ Utas Akhan. ${ }^{1}$ Pediatric Nursing, Bulent Ecevit University, Zonguldak, Turkey; ${ }^{2}$ Nursing, Karadeniz Technical University, Trabzon, Turkey; ${ }^{3}$ Nursing, Uludag University, Bursa, Turkey; ${ }^{4}$ Psychiatric Nursing, Bulent Ecevit University, Zonguldak, Turkey

\subsection{6/archdischild-2014-307384.1567}

Background and aims As in developed countries all over the world, the internet is also utilised in developing countries in all educational activities to increase the students' interest and motivation at class, achieve permanence of knowledge, and keep pace with technologic developments. The purpose of this study was to determine the unethical behaviours of high school

\begin{tabular}{|c|c|c|c|c|}
\hline & $X \pm S D$ & $\mathrm{x} /$ number of items & Maximum & Minimum \\
\hline Intellectual property & $29.16 \pm 13.89$ & $1.94 \pm 0.92$ & 75.00 & 15.00 \\
\hline Social impact & $30.86 \pm 14.36$ & $1.71 \pm 0.79$ & 90.00 & 18.00 \\
\hline Security and quality & $21.91 \pm 10.10$ & $1.56 \pm 0.72$ & 70.00 & 14.00 \\
\hline Network accuracy & $14.77 \pm 6.37$ & $1.84 \pm 0.79$ & 40.00 & 8.00 \\
\hline Information accuracy & $6.98 \pm 3.63$ & $1.74 \pm 0.90$ & 20.00 & 4.00 \\
\hline UEBS total & $103.70 \pm 43.71$ & & 295.00 & 59.00 \\
\hline
\end{tabular}

students in terms of internet use in the field of information technology as well as the factors that influence these behaviours.

Methods This study was population-based cross-sectional study. Research data were collected between February 13th and June 30 th of 2012. The universe of research consisted of 900 students studying at five different high schools located in Zonguldak, Turkey, whereas 643 students (86 girls, 557 boys) constituted the actual sampling.

Results The average total score was $103.70 \pm 43.71$. The students scored highest in the field of intellectual property, whereas the lowest scores could be observed in the sub-aspect of security and quality. No significant difference could be observed between the students' intellectual property scores according to their branch. However the results revealed significant differences in terms of social impact, network accuracy, security and quality, and information accuracy.

Conclusion The students' age is influential on their unethical use of information technologies. Along with basic computer training, teachers are supposed to raise the students' awareness with regard to ethical issues that arise from computer technologies and are of particular concern to the society, and teach them how they should act in terms of ethical problems.

\section{PO-0947 ESTABLISHING MULTIDISCIPLINARY MEDICAL ETHICS AND LAW TRAINING IN A CHILDREN'S HOSPITAL}

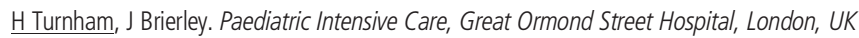

\subsection{6/archdischild-2014-307384.1568}

Introduction Legal and ethical controversies are commonly encountered by staff working in hospitals for children and continued education in these is important. ${ }^{1}$ The multidisciplinary team includes social workers and religious leaders amongst others. However, education in medical law and ethics is not often delivered in a multidisciplinary setting.

Following a successful season of small group sessions introducing legal and ethical topics to junior doctors, it became clear that there was wider interest within the hospital.

The advantage of teaching ethics and law in small groups is the participation of the audience who offer fresh perspectives. We wanted to develop a system to teach larger, multidisciplinary audiences while maintaining audience participation.

Methods A series of six interactive lectures was delivered by a mix of medical, legal and religious speakers. Live audience response system (ARS) was utilised to gauge real time reactions to ethical and legal problems. We also used the ARS to evaluate audience feedback.

Results Of attendees 55\% were clinical, 36\% non clinical and 9\% students. 91\% regularly or occasionally faced ethical challenges at work. $89.5 \%$ would recommend the lectures to a colleague and $87.4 \%$ were inspired to learn more about medical law and ethics.

Conclusion Both clinical and non-clinical professionals face ethical and legal problems as a team and have an interest in continued education. Delivering training to a large multidisciplinary team with limited resource's while maintaining group interaction is a challenge. We were able to deliver a successful, interactive, multidisciplinary lecture series using an ARS. 